\section{Research Article}

(C) 2021 Michal Beno.

This is an open access article licensed under the Creative Commons Attribution-NonCommercial 4.o International License

(https://creativecommons.org/licenses/by-nc/4.o/)

\title{
On-Site and Hybrid Workplace Culture of Positivity and Effectiveness: Case Study from Austria
}

\author{
Michal Beno \\ Institute of Technology and Business in Ceske Budejovice, \\ Okružní 517/10, 370 o1 České Budějovice, \\ Czechia
}

DOI: https://doi.org/10.36941/ajis-2021-0142

\section{Abstract}

Workplace culture includes beliefs, attitudes, practices, rules, norms and customs. Ideal workplace culture focuses on activities that generate and demonstrate trust. A strong form of essential values that all employees respect and practice helps to build the positivity and effectiveness of a workplace environment. This paper examines the positivity and effectiveness of an on-site and hybrid working model from Austria. A research question is raised that concerns the difference between negative and positive approaches towards different working environments when following the aspects of respect and dignity, support, caring, rewards, forgiveness and inspiration, and asks whether these differ fundamentally and represent different theoretical mechanisms. Mixed research methods (quantitative and qualitative) using the medium of WhatsApp were applied. Relying on Chi-squared tests, we detected significant differences in 25 out of 29 statements where hybrid workers are more often supporting, caring, rewarding, forgiving and inspiring than cubicle workers. In four cases, the test did not detect any significant difference of respect and dignity dimensions: treating each other with respect, demonstrating integrity, fostering dignity in one another and showing appreciation for one another. Evidently, as shown by the data obtained, organisations that offer a hybrid working model have a very high score of positivity and effectiveness in providing the best place to work. The hybrid model might be an inevitable arrangement for some organisations. The interview data present a clearer picture of some pros and cons. The current data seem to reveal that these benefits persist as companies shift to hybrid working at scale and at pace.

Keywords: on-site and hybrid workplace culture, positivity, effectiveness, Austria

\section{Introduction}

The Covid-19 pandemic has been a turning point in our society, especially in the healthcare and business (lockdowns and e-working) sectors. For some European countries (Finland, the Netherlands, Luxembourg, Austria), the move to an e-working operating environment was not entirely new and had already been underway in the pre-pandemic era (Eurostat, 2021). As a recent Eurofound (2020) survey reveals, most European Union employees reported a positive experience with teleworking during the first phase of Covid-19, but very few of them wish to work in this way all the time and would prefer a hybrid working option. Recent research from Hays reveals that over half the employees will change over to a hybrid working model (Franklin, 2020). A hybrid workforce can be 
defined as a workforce distributed partly across different locations and partly in traditional cubicles and factory spaces. This means that this model of working is characterised by flexibility and choices. Even in the manufacturing sector which, in the past tended to be more location-dependent, more than half the businesses utilise some degree of flexible working (IWG, 2019). Recently published data highlight the fact that more than one-third of respondents want to extend the working-from-home period to at least 1-2 years, and $28.57 \%$ want to continue with hybrid e-working (Beno et al., 2021). Another survey stresses that hybrid working is driving the office footprint strategy (PWC, 2021).

The ideal workplace culture focuses on activities that generate and demonstrate trust. A strong variety of essential values that all employees respect and practice helps to build the positivity and effectiveness of the workplace environment.

To understand the evolution of cubicle working into a hybrid working environment, we surveyed five organisations with 30 cubicle employees and another five organisations with 30 hybrid employees from different service sectors in Austria. Additionally, semi-structured interviews with five managers about the pros and cons of the hybrid office model were conducted. Thus, an important research question arises that concerns the difference between negative and positive approaches towards different working environments when following the aspects of respect and dignity, support, caring, rewards, forgiveness and inspiration, and asks whether these differ fundamentally and represent different theoretical mechanisms.

The next section presents a literature review consisting of a selection of literature and definitions of the concept relevant to the subject. The methodology is introduced in the second part. Then follows a section presenting the results of the study. The fourth section is the discussions, and the last part gives a summary.

\section{Workplace Culture and Hybrid Working}

In today's modern workplace where five different generations work together, with different perceptions of work ethics, the workplace culture may look like effective people management practice.

Schein (2004, p. 11) highlights that "the only thing of real importance that leaders do is to create and manage culture; that the unique talent of leaders is their ability to understand and work with culture; and that it is an ultimate act of leadership to destroy culture when it is viewed as dysfunctional." Deal and Kennedy (1982) proposed one of the first models of "organisational culture (the tough guy, macho culture; the work hard/play hard culture; the bet-your-company culture and the process culture, (p. 107-108))." Rousseau (1990) proposed a multi-layered model structured as rings to trap the determinants of every culture, a process that is described as follows: "a continuum from unconscious to conscious, from interpretative to behaviour, from inaccessible to accessible" (p. 158). Another relevant model is Herman's so-called "Cultural Iceberg" to describe the workings of a culture (Herman, 1978). Organisational culture relates to the set of values, beliefs and behaviour patterns that forms the core identity of an organisation (Denison, 1984). Thus, workplace culture can be seen as the general nature of business, including values, beliefs, behaviours, goals, attitudes, work rules and practices. Ideally, it is viewed as positive by employers and employees. Simply, workplace culture is to an organisation what personality is to an individual (Schuneman, 2019). A recent study demonstrates that different working cultures also lead to different expansions of e-working (Beňo, 2021a, p. 23).

In the pre-Covid-19 period, the Home-Office-School environment proved to be a bonus (Beno, 2021). The modern strategy being explored is hybrid working, which was recently defined by Beno et al. (2021) as a mixture of home and cubicle working, working in a hybrid model combining remote and in-person work. This is similar to the situation defined by Grzegorczyk et al. (2021) as follows: "in a hybrid model, workers can telework for a proportion of their contracted working hours within the limits of individually or collectively negotiated work arrangements" (p. 11). A hybrid workforce can be defined as a workforce distributed partly across different locations and located partly in traditional 
cubicles and factory spaces. This means that this model of working is characterised by flexibility and choices. Hybrid work models will allow organisations to recruit talent better, achieve innovation and create value for all (Hilberath et al., 2020). Further, based on current data, the absence of commuting in the case of WFH and hybrid model strategies simply means higher individual productivity (Beno and Hvorecky, 2021). It has been found that the following hybrid models are being offered to employees: at-will employment (Ruud and Becker, 2012), split weeks (Singleton, 2020), shift work (Van de Ven, 2017) and flexible work week (Lyons, 2020).

\section{Methods}

Firstly, the existing literature on workplace culture and hybrid working is discussed. Secondly, a cross tabulation of the data was made. Research was performed by means of a quantitative approach (Chisquared test) with a target group sample of 6o individuals (employees in Austria) and a qualitative approach with five managers of hybrid workers. Mixed research methods add further detail and description, which increases the validity of the findings (Van Zoonan, 1994). In this paper, the medium of WhatsApp was used as an alternative platform (Singer et al., 2020) to collect data for analysis. According to statistics compiled by DMR (2021), this tool has 2 billion WhatsApp users. In addition, this medium allows researchers to document participant experiences at no cost.

The control variables were age (ranging from 22 to 55 years) and gender $(43.08 \%$ female and $56.92 \%$ male). WhatsApp conversation data were taken from 60 professionals and five managers of hybrid workers (participants A to E). The professionals were from different occupational fields, including customer services, computers and programming, sales, teaching and tutoring.

A quantitative analysis is done to find the difference between negative and positive approaches toward different working environments in the aspects of respect and dignity, support, caring, rewards, forgiveness and inspiration, and a qualitative analysis was done to analyse the pros and cons of the hybrid office model.

In the first stage of our survey, we identified full cubicle and hybrid workers. Secondly, we examined six components using data from Cameron et al. (2011) in relation to the 29 statements. A two-point scale was used: $1=$ yes, $2=$ no. Thirdly, for qualitative analysis, data were categorised in terms of the pros and cons of hybrid working.

\section{Results}

\subsection{Positive practice indicators}

Table 1 provides positive practice dimensions with 29 statements of both types of employees. Almost in all the dimensions, we observe more positive practices for hybrid workers than for cubicle workers. Only in three cases (positions marked in bold) are positive practices of respect and dignity for both types of workers seen.

Table 1: Positive Practices Dimensions cubicle and hybrid workers.

\begin{tabular}{|c|c|c|c|c|c|}
\hline & & \multicolumn{2}{|c|}{$\begin{array}{c}\text { Cubicle } \\
\text { Workers }\end{array}$} & \multicolumn{2}{|c|}{$\begin{array}{l}\text { Hybrid } \\
\text { Workers }\end{array}$} \\
\hline & & Yes & No & Yes & No \\
\hline \multirow{7}{*}{$\begin{array}{l}\text { Respect and } \\
\text { dignity }\end{array}$} & \multirow{7}{*}{$\begin{array}{l}\text { We treat one another with respect } \\
\text { We demonstrate integrity } \\
\text { We express gratitude to one another } \\
\text { We foster dignity in one another } \\
\text { We show appreciation for one another } \\
\text { We trust one another } \\
\text { We display confidence in one another }\end{array}$} & 30 & $\mathbf{0}$ & 30 & o \\
\hline & & 30 & $\mathbf{0}$ & 30 & $\mathbf{o}$ \\
\hline & & 20 & 10 & 30 & 0 \\
\hline & & 30 & $\mathbf{0}$ & 30 & o \\
\hline & & 15 & 15 & 22 & 8 \\
\hline & & 5 & 25 & 22 & 8 \\
\hline & & 5 & 25 & 22 & 8 \\
\hline
\end{tabular}




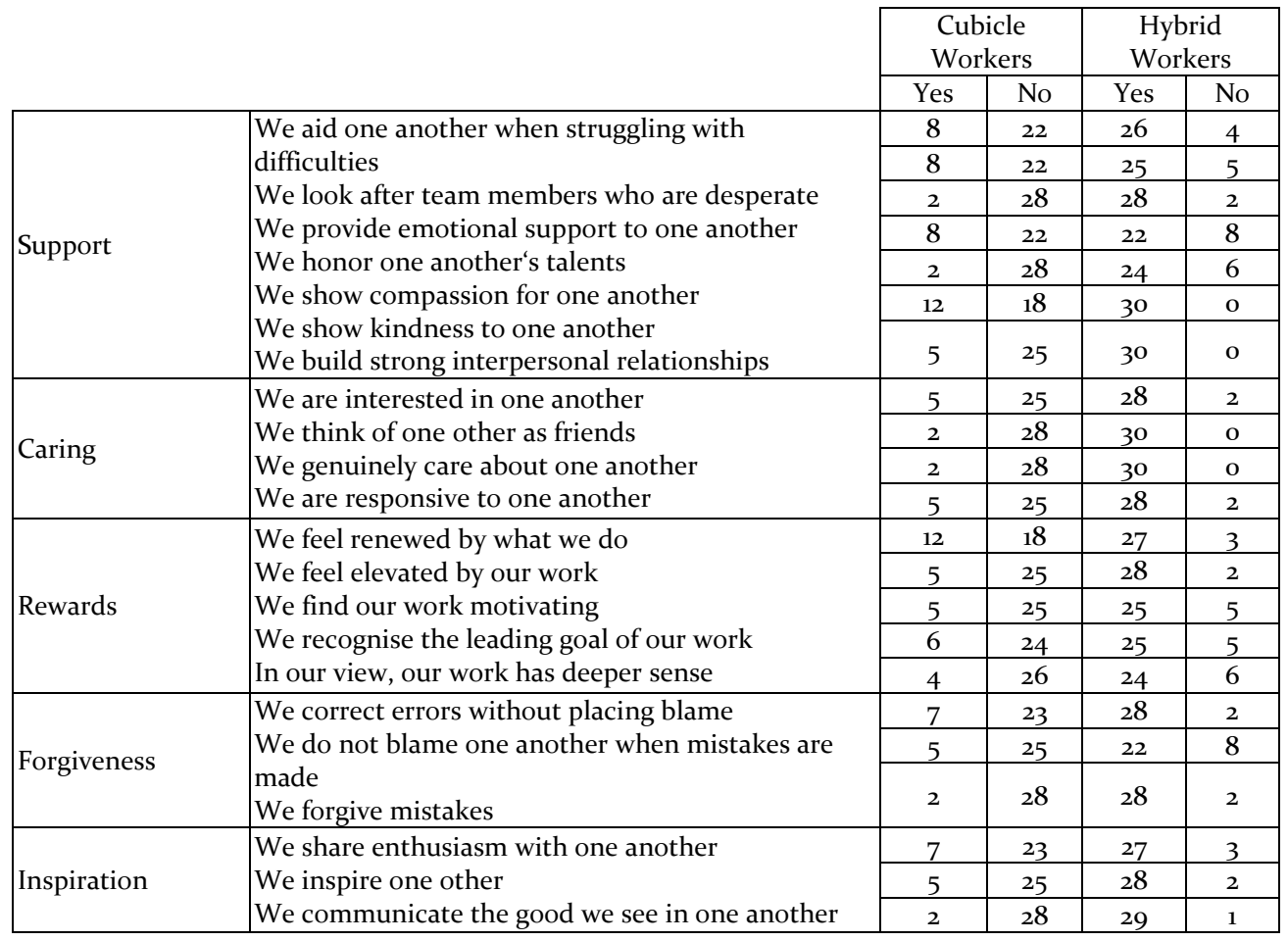

Source: Author's own elaboration

Additionally, Table 2 reports descriptive statistics data, Chi-squared test results. The aim of using this test was to find a significant difference between cubicle and hybrid workers working partly on site and partly at home.

Table 2: Chi-squared test results

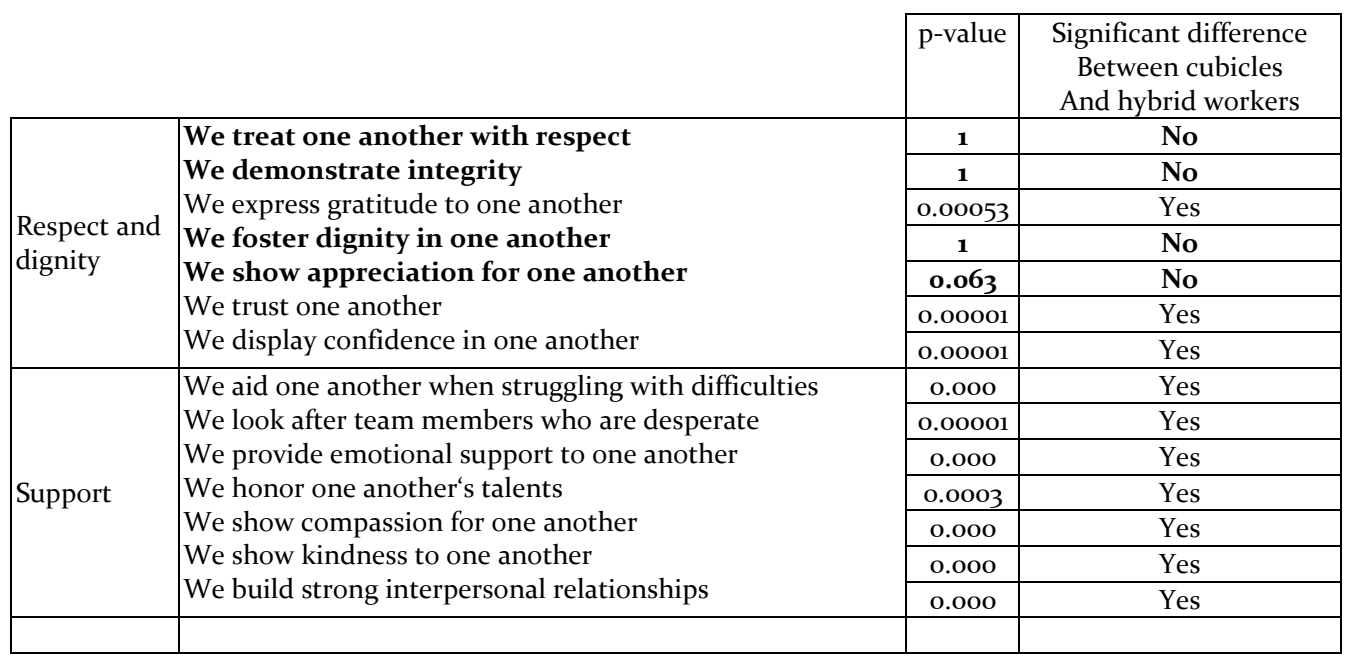




\begin{tabular}{|c|c|c|c|}
\hline & & p-value & $\begin{array}{l}\text { Significant difference } \\
\text { Between cubicles } \\
\text { And hybrid workers }\end{array}$ \\
\hline \multirow[t]{4}{*}{ Caring } & \multirow{4}{*}{$\begin{array}{l}\text { We are interested in one another } \\
\text { We think of one other as friends } \\
\text { We genuinely care about one another } \\
\text { We are responsive to one another }\end{array}$} & 0.000 & Yes \\
\hline & & 0.000 & Yes \\
\hline & & 0.000 & Yes \\
\hline & & 0.000 & Yes \\
\hline \multirow{5}{*}{ Rewards } & \multirow{5}{*}{$\begin{array}{l}\text { We feel renewed by what we do } \\
\text { We feel elevated by our work } \\
\text { We find our work motivating } \\
\text { We recognise the leading goal of our work } \\
\text { In our view, our work has deeper sense }\end{array}$} & 0.00005 & Yes \\
\hline & & 0.000 & Yes \\
\hline & & 0.000 & Yes \\
\hline & & 0.000 & Yes \\
\hline & & 0.000 & Yes \\
\hline \multirow{3}{*}{ Forgiveness } & \multirow{3}{*}{$\begin{array}{l}\text { We correct errors without placing blame } \\
\text { We do not blame one another when mistakes are made } \\
\text { We forgive mistakes }\end{array}$} & 0.000 & Yes \\
\hline & & 0.00001 & Yes \\
\hline & & 0.000 & Yes \\
\hline \multirow{3}{*}{ Inspiration } & \multirow{3}{*}{$\begin{array}{l}\text { We share enthusiasm with one another } \\
\text { We inspire one another } \\
\text { We communicate the good we see in one another }\end{array}$} & 0.000 & Yes \\
\hline & & 0.000 & Yes \\
\hline & & 0.000 & Yes \\
\hline
\end{tabular}

Source: Author's own elaboration

By relying on Chi-squared tests, we detected significant differences in 25 out of 29 statements where hybrid workers are more often supporting, caring, rewarding, forgiving and inspiring than cubicle workers. Furthermore, hybrid workers treat each other with respect, trust one another and display confidence in one another much more often.

In four cases, the test did not detect any significant difference in the respect and dignity dimensions: treating each other with respect, demonstrating integrity, fostering dignity in one another and showing appreciation for one another, as shown in Table 2 (positions marked in bold). This is similar to the statement in the study by Tiwari and Sharma (2019) that "dignity is not a word but a lens through which (a) manager can analyze the workplace problems and find appropriate solutions" (p. 9). The respectful treatment of all employees at all levels was rated as "very important" by $72 \%$ of those surveyed, making it the top contributor to overall employee job satisfaction (SHRM, 2014, p. 7).

Evidently, as shown by the data, organisations offering hybrid working models have a very high score of positivity and effectiveness in providing the best place to work. In the pre-Covid-19 era, the workplace was already being changed by technology, digitisation and skills availability. A study in the Worcester Business Journal reveals that when employees believe leaders are actively trying to create a more humane workplace, the overall culture metrics improve, including $89 \%$ of employees who said they felt their company cared about them as people (Mosley, 2016). In this study, the hybrid working environment clearly shows genuine care for others. Another study showed that $88 \%$ of people said that expressing gratitude to colleagues makes them feel happier and more fulfilled (Palmer, 2017). But in our study, hybrid workers express gratitude to each other much more.

The office culture and the mixed office (including flexibility) culture need social interaction and connection. Based on the data from a hybrid working employee's standpoint, this connectivity is more tied to the company's vision, purpose and culture.

\subsection{Pros and cons of hybrid working}

In this section, we explore the benefits and disadvantages of the hybrid working model. It was revealed that some companies cannot afford full e-working, so their offices remain open. All the participants stated that "most of the organisation's work is not suitable for fully remote work". They further added that the reaction to this was "somewhat of a balance between the two working options, 
the hybrid workplace model". This model was explained by respondent B as follows: "Our employees can enjoy the benefits of working in a home office, while still maintaining social interactions in the cubicle." In the same vein, participant A explains this model as follows: "The hybrid model balances remote and on-site office work." It appears evident that this hybrid working environment requires "on-site office versus home office space but also a mix of we versus me space," as stated by participants $C$ and D. In comparison with this, participant $E$ said, "having the right mix of different flexible models is equal to achieving a hybrid working model."

Throughout the interviews, all the participants expressed the feeling that though working remotely may sound good in theory, it is very problematic to carry out effectively in practice. Therefore, participants were asked to comment on the pros and cons of the hybrid model. As a result, respondent A said, "it starts with a great possibility of reducing costs." Additionally, "as employees become more comfortable with working outside the office premises, they are obviously more productive as they do not have to commute and have more time to spend with their family." Similarly, respondents B and D agree that "a hybrid working model helps alleviate the stress that comes from commuting." Furthermore, participant C commented on productivity, stating "it makes employees more productive, which comes from the satisfaction of the tandem of their work and lives". "The pros include improved employee retention, more access to talent and lower office costs," participant E said.

The findings from this study indicate that the drawbacks stem from less social contact and difficulty with tools and communication. According to respondent B, "what seems to be an advantage at the beginning can finish by being a disadvantage." But A and $C$ mentioned that "the managers of the past are not necessarily equipped to manage in this modern workplace world." Likewise participant D said, "work traditionally meant a cluster of workers in a centralised location." Respondent E added that "the managers of tomorrow will require a much different skills set." It is clear that all participants who displayed IT problems had to be separated before the hybrid transition. It was also evident that participants were concerned about missing out on conversations and office interaction in a situation of isolation. Participants A and B stated that "the relationships and camaraderie built through being physically present in the office may be lost."

\section{Discussion}

House (1981) characterises work as "the most structured and organized" angle of "most adults' life" (p. 8). Human beings are oriented to social interaction. Social interaction at the workplace is difficult for many individuals, especially during Covid-19 (Eddy, 2021). Research findings from Forbes (ForbesInsights, 2009) demonstrated that face-to-face interaction of executives is preferable. But based on our data, the hybrid model found a way to build compatibility and a sense of working together by keeping remote and in-cubicle participants on an equal footing. There is a new strategy for working going forward. Should it be everyone back in the office, everyone working from home, working from anywhere or working partly at home and partly in the office? Our data show how our teams (just in-office or hybrid) can best get their different types of work done. In the remote work environment, which lacks physical presence, human interaction and body language, cooperation and interaction are more important than ever. It can be observed that hybrid working helps to decrease toxic work place cultures. A recent study found that $90 \%$ of workers would not consider joining a company if they had a higher salary, but the company had a bad work culture (Howitislike, 2020). Furthermore, Google will test a hybrid work-from-home model (Elias, 2020). A recent study confirms the high demand (28.57\%) for hybrid e-working (Beňo, 2021b; Beno et al., 2021). The practice of learning to forgive and showing how much help we can offer to others (Luskin, 2003, p. 72) appears to be more easily implemented in a hybrid working model, as shown in the data obtained. Evidently, in the on-site workplace, forgiveness has no place. The management of fully on-site or fully remote businesses, or even those somewhere in between, should give full attention to the potential advantages and drawbacks of the hybrid working model, a question highlighted in the interviewee 
data. It is quite clear that this would be beneficial for organisations (Harker Martin and MacDonnell, 2012).

\section{Conclusion}

This study estimates the impact of the evolution of cubicle working into a hybrid working environment in five organisations with 30 cubicle employees and five organisations with 30 hybrid employees from different service sectors in Austria. Additionally, semi-structured interviews with five managers about the pros and cons of the hybrid office model were conducted. The study was conducted in two stages. The first stage investigated the quantitative data and the second stage analysed the qualitative data. The findings of the quantitative and qualitative data were applied in order to answer the research question and achieve the objectives of this study.

The main research question investigated in this paper concerns the difference between negative and positive approaches toward different working environments while following the aspects of respect and dignity, support, caring, rewards, forgiveness and inspiration, and asking whether these differ fundamentally and represent different theoretical mechanisms.

The hybrid work model contributes to positivity, efficiency and variation of work for sustaining a sense of mixed work techniques among office changes. Nowadays, many organisations are hurriedly adopting different flexible work-from-home policies, and a hybrid work environment is absolutely necessary. Furthermore, the findings of this study suggest that the advantages of the hybrid e-work model extend to the office as well. Organisations are responsible for finding a work model that yields the best remote and on-site work and provides experiences of positivity, effectiveness and flexibility.

In conclusion, it is clear from the findings that the overall hybrid working model is positive and effective compared to the cubicle worker model. However, in four cases, the test did not detect any significant difference in these dimensions of respect and dignity: treating one another with respect, demonstrating integrity, fostering dignity in one another and showing appreciation for one another.

There is still some potential for future research in this area. We propose future research on this topic to include a sample of full-time workers with gender equality. Additionally, future research could usefully also investigate this issue by employing a wider sample to be investigated.

\section{References}

Beňo, M. (2021a). E-working: Country Versus Culture Dimension. AGRIS on-line Papers in Economics and Informatics 13(2), 23-34. DOI 10.7160/aol.2021.130202

Beňo, M. (2021b). Commuting to work versus e-commuting: data from an Austrian company in pre-COVID-19 era, during ist lockdown, after easing and during and lockdown. AD ALTA, Journal of Interdisciplinary Research 11(1), 25-31. DOI: 10.33543/11012531

Beno, M. (2021). Working from the Home Office and Homeschool(-ing): Experiences of Austrian Employees (Parents) in the Time of Covid-19. Journal of Educational and Social Research, 11(4), 73-83. https://doi.org/10.36941/jesr-20210078

Beno, M. \& Hvorecky, J. (2021). Data on an Austrian Company's Productivity in pre-Covid-19 Era, during the Lockdown and after Its Easing: to Work Remotely or Not? Frontiers in Communication, 6( 641199), 1-10, doi: 10.3389 /fcomm.2021.641199

Beno, M., Hvorecky, J. \& Caganova, D. (2021). An Optimal e-working Environment: Online Survey Results. IJBASS, 7(2), 1-10, DOI: 10.33642/ijbass.v7n2p1

Cameron, K., Mora, C., Leutscher, T. \& Calarco, M. (2011). Effects on Positive Practices on Organizational Effectiveness. The Journal of Applied Behavioral Science, 47(3), 266-308, https://doi.org/10.1177/o021886310395514

Deal, T. \& Kennedy, A. (1982). Corporate Cultures: The Rites and Rituals of Corporate Life. USA: Addison-Wesley Publishing Company.

Denison, D. R. (1984). Bringing corporate culture to the bottom line. Organizational Dynamics, 13(2), 5-22, https://doi.org/10.1016/oo9o-2616(84)90015-9

DMR. (2021). WhatsApp Statistics and Facts (2021). Retrieved from: https://expandedramblings.com/index.php/w hatsapp-statistics/ 
Eddy, C. M. (2021). The social impact of COVID-19 as perceived by the employees of a UK mental health service. International Journal of Mental Health Nursing, 1-10. https://doi.org/10.1111/inm.12883

Elias, J. (2020). Google will try 'hybrid' work-from-home models, as most employees don't want to come in every day. Retrieved from: https://www.cnbc.com/2020/o9/23/google-ceo-sundar-pichai-considering-hybridwork-from-home-models.html

Eurofound. (2020). COVID-19. Living, working and COVID-19. Luxembourg: Publications Office of the European Union.

Eurostat (2021). Employed persons working from home as a percentage of the total employment, by sex, age and professional status (\%). Retrieved from: http://appsso.eurostat.ec.europa.eu/nui/show.do?query=BOOKMARK_DS-052914_QID_6EoBB9BE_UID_3F171EBo\&layout=TIME,C,X,o;GEO,L,Y,o;SEX,L,Z,o;FREQUENC,L,Z,1;AGE,L,Z,2;WSTATUS,L,Z,3;UNIT,L,Z,4 ;INDICATORS,C,Z,5;\&zSelection=DS-052914WSTATUS,EMP;DS-052914FREQUENC,USU;DS052914INDICATORS,OBS_FLAG;DS-052914AGE,Y15-64;DS-052914SEX,T;DS052914UNIT,PC;\&rankName1=WSTATUS_1_2_-1_2\&rankName2=TIME_1_o_o_o\&rankName3=UNIT_1_2_1_2\&rankName4=GEO_1_2_o_1\&rankName5=AGE_1_2_-1_2\&rankName6=FREQUENC_1_2_1_2\&rankName7=INDICATORS_1_2_-1_2\&rankName8=SEX_1_2_-1_2\&sortC=ASC_1_FIRST\&rStp=\&cStp=\&rDCh=\&cDCh=\&rDM=true\&cDM=true\&footnes=false\&empty=false\&wai=false\&time _mode=ROLLING\&time_most_recent=false\&lang=EN\&cfo=\%23\%23\%23\%2C\%23\%23\%23.\%23\%23\%23

ForbesInsights. (2009). Business Meetings. The Case for Face-to-Face. Retrieved from: https://images.forbes.com/forbesinsights/StudyPDFs/Business_Meetings_FaceToFace.pdf

Franklin, N. (2020). Half of firms set to adopt flexible working. Retrieved from: https://workplaceinsight.net/halfof-firms-set-to-adopt-flexible-working/?utm_source=rss\&utm_medium=rss\&utm_campaign=half-of-firmsset-to-adopt-flexible-working

Grzegorczyk, M., Mariniello, M., Nurski, L. \& Schraepen, T. (2021). Blending the physical and virtual: a hybrid model for the future of work. Policy Contribution 14/2021, Bruegel, 1-22.

Harker Martin, B. \& MacDonnell, R. (2012). Is telework effective for organizations? A meta-analysis of empirical research on perceptions of telework and organizational outcomes. Management Research Review, 35(7), 602-616, https://doi.org/10.1108/01409171211238820

Herman, S. H. (1978). TRW Systems Group. In French, W. L. \& Bell, C. H. Organisation Development: Behavioural Science Intervention for Organisation Improvement, and Ed. Englewood Cliffs: Prentice Hall, p.16.

Hilberath, Ch., Kilmann, J., Lovich, D., Tzanetti, T., Bailey, A., Beck, S., Kaufman, E., Khandelwal, B., Schuler, F. \& Woolse, K. (2020). Hybrid Work Is the New Remote Work. Retrieved from: https://webassets.bcg.com/c6/fe/e4f52117436oa21f280425ao4613/bcg-hybrid-work-is-the-new-remote-work-sep2020.pdf

House, J. S. (1981). Work stress and social support. Reading, MA: Addison-Wesley.

Howitislike. (2020). Why Toxic Work Cultures Make Best People Quit. Retrieved from: https://www.howsitlike.com/blog/Why-Toxic-Work-Cultures-Make-Best-People-Quit

IWG. (2019). THE IWG GLOBAL WORKSPACE SURVEY. Welcome to Generation Flex- the employee power shift. Retrieved from: https://assets.regus.com/pdfs/iwg-workplace-survey/iwg-workplace-survey-2019.pdf

Luskin, F. (2003). Forgive for Good. New York: HarperCollins Publishers Inc.

Lyons, K. (2020). Google pushes return to office to September and will test flexible work week. Retrieved from: https://www.theverge.com/2020/12/14/2217515o/google-return-office-september-flexible-work-weekcoronavirus-pandemic-sundar-pichai

Mosley, E. (2016). The human need for recognition in the workplace. Retrieved from: https://www.wbjournal.com/article/the-human-need-for-recognition-in-the-workplace

Palmer., B. (2017). How to Express Gratitude at Work. Retrieved from: https://www.pcma.org/gratitudeworkplace/\#: :text=Other\%2ostatistics\%2oon\%2ogratitude\%2oin,harder\%2ofor\%2oa\%2ograteful\%2oboss

PWC. (2021). It's time to reimagine where and how work will get done. Retrieved from: https://www.pwc.com/us/en/library/covid-19/us-remote-work-survey.html

Rousseau, D. M. (1990). Assessing organizational culture: The case for multiple methods. Organizational climate and culture, $153,192$.

Ruud, J. K. \& Becker, W. S. (2012). Employment-at-Will. The Encyclopedia of Human Resource Management: Short Entries, 32, https://doi.org/10.1002/9781118364741.ch32

Schein, E. H. (2004). Organizational Culture and Leadership, Thirdedition. San Francisco: Jossey-Bass.

Schuneman, F. (2019). The Importance of Workplace Culture. Retrieved from: https://www.invistaperforms.org/the-importance-of-workplace-culture/ 
SHRM. (2014). Employee Job Satisfaction and Engagement. Retrieved from: https://www.shrm.org/resourcesandtools/business-solutions/documents/2015-job-satisfaction-andengagement-report.pdf

Singer B., Walsh C. M., Gondwe L., Reynolds, K., Lawrence, E. \& Kasiya, A. (2020). WhatsApp as a medium to collect qualitative data among adolescents: lessons learned and considerations for future use. Gates Open Research, 4(13), https://doi.org/10.12688/gatesopenres.13169.1

Singleton, A. (2020). Introduce split three-day week to get Britain back to work, RSA urges. Retrieved from: https://www.thersa.org/press/releases/2020/introduce-split-three-day-week-to-get-britain-back-to-workrsa-urges

Tiwari, A. \& Sharma R. R. (2019). Dignity at the Workplace: Evolution of the Construct and Development of Workplace Dignity Scale. Front. Psychol 10(2581), 1-12. doi: 10.3389/fpsyg.2019.02581

Van de Ven, H. A. (2017). Shift your work: Towards sustainable employability by implementing new shift systems. Rijksuniversiteit Groningen.

Van Zoonan, L. (1994). Feminist Media Studies. London and New York: Sage. 